\title{
Administration of recombinant thrombomodulin before progression of disease causing disseminated intravascular coagulation might be better compared with administration after progression of disease
}

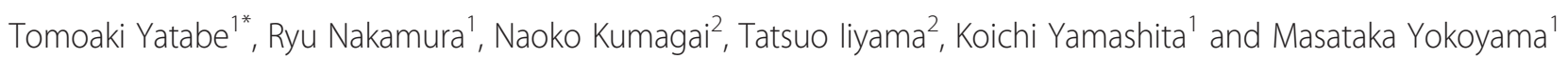

\begin{abstract}
Background: As disseminated intravascular coagulation (DIC) causes multiple organ failure, recombinant thrombomodulin (rTM) is widely used in Japan for treating DIC. However, the optimal timing of rTM administration has not yet been determined. We hypothesized that the administration of rTM before progression of disease causing DIC might be better for the treatment of DIC than that after progression of disease.

Methods: A total of 101 patients received rTM in the intensive care unit (ICU) between August 2008 and November 2013 were enrolled. Depending on survival at hospital discharge, the patients were divided into survivor (group S) and non-survivor groups (group NS). Patient characteristics before DIC development, acute physiology and chronic health evaluation II (APACHEII) score and sequential organ failure assessment (SOFA) score at the start of rTM administration, rTM administration dose, duration of time between the onset of disease causing DIC and rTM administration, and combination therapy were collected.

Results: Group S had 57 patients, and group NS had 44 patients. More than $70 \%$ of patients in group S were administrated rTM within 1 day from the onset of disease causing DIC (0 days, 40\% vs 20\%; 1 day, 33\% vs 30\%; more than 2 days, $26 \%$ vs 50\%). At the start of the rTM administration, the APACHEII and SOFA scores were significantly lower in group $S$ ( $26 \pm 6$ vs $32 \pm 6, p<0.001 ; 9.5 \pm 4.2$ vs $13.4 \pm 3.6, p<0.001)$. Multivariate logistic regression analysis of outcomes was performed. The duration of time between the onset of disease causing DIC and rTM administration, the APACHEII score, the SOFA score, and use of continuous renal replacement therapy (CRRT) were selected as candidate variables $(p<0.05)$. The SOFA scores and use of CRRT were highly correlated with the APACHEII score (Pearson correlation $=0.63$ and 0.43 , respectively). Therefore, the SOFA score and the use of CRRT were excluded from this model. Late administration of rTM (more than 2 days between the onset of disease and rTM administration) was associated with undesirable outcome (odds ratio $=3.36,95 \%$ confidence interval $=1.03-10.92, p=0.044$ ).

Conclusions: This study suggested that the administration of rTM before the progression of disease causing DIC might be better than that after progression of disease causing DIC. Further randomized clinical trials are required to elucidate whether early administration of rTM is actually effective.
\end{abstract}

Keywords: Recombinant thrombomodulin, Disseminated intravascular coagulation, Retrospective analysis

\footnotetext{
* Correspondence: yatabe@kochi-u.ac.jp

'Department of Anesthesiology and Intensive Care Medicine, Kochi Medical

School, Kohasu, Oko-cho, Nankoku City, Kochi 783-8505, Japan

Full list of author information is available at the end of the article
} 


\section{Background}

Disseminated intravascular coagulation (DIC) occurs in $9 \%-19 \%$ of patients in the intensive care unit (ICU), and rate of mortality associated with DIC is as high as $45 \%-$ $78 \%$ [1]. The development of new therapies to treat DIC is expected because this rate has not changed in the last 10 years [1]. In Japan, recombinant human soluble thrombomodulin-alpha (rTM) (Recomodulin, Asahi Kasei Pharma, Tokyo, Japan) has been available as a therapeutic DIC drug since 2008. This drug binds to thrombin to inactivate coagulation [2]. In addition, rTM promotes protein $\mathrm{C}$ activation by thrombin, resulting in the formation of activated protein $\mathrm{C}$ (APC) [2]. APC in turn inhibits thrombin generation by inactivating coagulation factors $\mathrm{Va}$ and VIIIa to inhibit the activation of the blood coagulation system [2]. In our ICU, rTM has been used as the first-line drug for the treatment of DIC because it is more effective than heparin and has fewer bleeding-related side effects [2]. Recently, the safe use of rTM for ICU patients has been reported in a phase IIb study of rTM [3]. Another study had shown that rTM may be superior to conventional DIC treatments in patients in the ICU [4]. However, the optimal timing of rTM administration has not yet been determined. We hypothesized that the administration of rTM before the progression of disease causing DIC might be better for the treatment of DIC than that after progression of disease causing DIC. Therefore, we investigated whether the timing of rTM administration was associated with differences between survivors and non-survivors in a retrospective analysis.

\section{Methods}

\section{Ethics statement}

This study was approved by the ethics committee of Kochi Medical School, and the need to obtain informed consent was waived because this study was a retrospective analysis. In our hospital, every patient was able to declare refusing use of data from the present to the future in writing. Therefore, patients who refused the use of their record were excluded from the study.

\section{Patients}

The subjects included a consecutive series of patients with DIC who were treated with rTM in our ICU between August 2008 and November 2013. Of these patients, those $<18$ years of age and those who refused the use of their record at hospitalization were excluded from the study. Depending on survival at hospital discharge, the patients were divided into survivor (group S) and non-survivor groups (group NS).

\section{Diagnosis of DIC}

The diagnosis of DIC was based on the DIC criteria of the Japanese Association for Acute Medicine [5]. These diagnostic criteria consist of four items, namely, more than three items of the diagnostic criteria of systemic inflammatory response syndrome are satisfied, the platelet count, the prothrombin time ratio, and the concentration of fibrin/fibrinogen degradation products (Figure 1). Patients with a total score of $\geq 4$ were diagnosed as having DIC.

\section{The onset of disease causing DIC}

We defined the onset of disease causing DIC as the timing when individual physicians diagnosed it and wrote medical records.

\section{Treatment}

According to the drug information, the doses of rTM are defined as 380 and $130 \mathrm{U} / \mathrm{kg} /$ day for patients with non-impaired renal function and those with impaired renal function, respectively. However, the drug information does not define impaired renal function and recommends decrease to $130 \mathrm{U} / \mathrm{kg} /$ day if bleeding occurs in patients with impaired renal function. Therefore, individual physicians decided the doses of rTM in accordance with this recommendation and patient status. In addition, sepsis was treated in accordance with the Surviving Sepsis Campaign Guidelines [6,7], but the details were decided by individual physicians.

\section{Data collection}

The following data were obtained from electronic patient records: patient characteristics before DIC development, acute physiology and chronic health evaluation II (APACHEII) score and sequential organ failure assessment (SOFA) score at the start of rTM administration, rTM administration dose and duration, duration of time

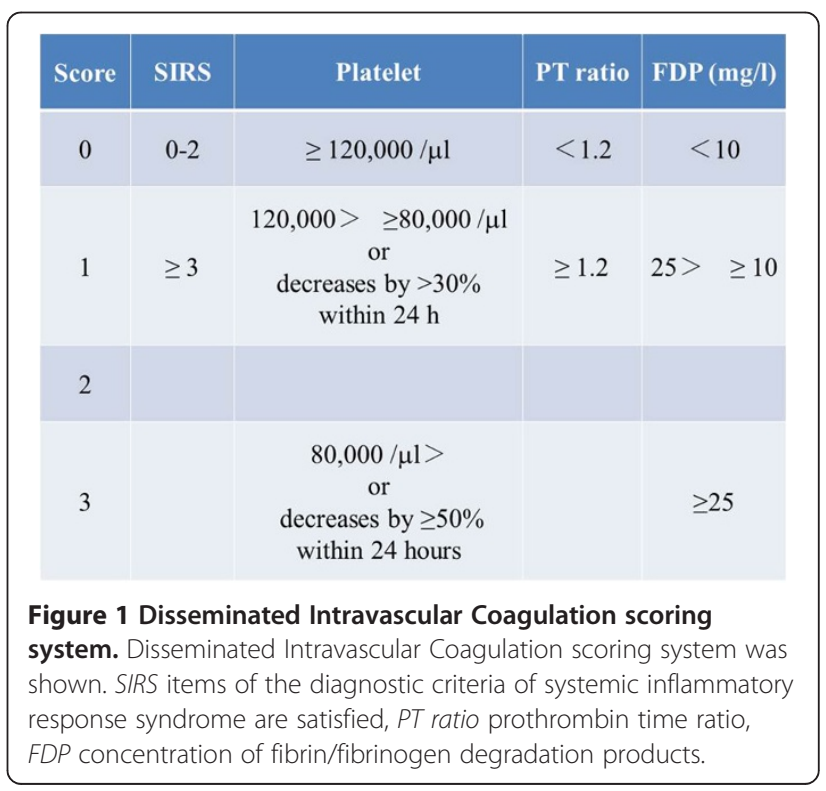


between the onset of disease causing DIC and rTM administration, and combination therapy.

\section{Statistical analysis}

Data are expressed as the mean \pm standard deviation. Associations between the outcome and baseline variables were examined by univariate analysis. For the analysis of continuous variables, a $t$ test was used, and a chi-square test was used to analyze categorical variables. Variables were considered potentially associated with outcome when $p<0.05$; these variables were further evaluated using a multivariate logistic regression model. The age was included in components of the APACHEII score. Therefore, it was excluded from this model. When the linearity assumptions considered were violated, continuous variables were divided into tertiles and analyzed as discrete variables. For all analyses, a two-sided $p$ value $<0.05$ was considered statistically significant. Favorableness of fit was evaluated using the Hosmer-Lemeshow test, and predictive ability was confirmed by c-statistics based on receiver operating characteristic analysis. Statistical analysis was performed using SAS version 9.3 (SAS Institute, Inc., Cary, NC, USA).

\section{Results}

\section{Patient characteristics}

A total of 105 patients received rTM in the ICU. Of these patients, 101 were analyzed; three patients $<18$ years of age and one patient who refused the use of his record were excluded from the study. Groups S and NS included 57 and 44 patients, respectively. Of the patient characteristics before the onset of DIC, data on heart disease, diabetes, hypertension, and the rate of smokers did not significantly differ between the groups (Table 1). However, the group NS had fewer women ( $47 \%$ vs $22 \%, p=0.011$ ) and a higher average BMI $(20 \pm 4$ vs $23 \pm 4, p<0.001)$ than the group $\mathrm{S}$. The age in group NS was higher than that in group $S(68 \pm 17$ vs $75 \pm 11, p=0.036)$.

\section{The relationship between DIC and administration of rTM}

The duration from the onset of disease causing DIC to rTM administration in group $\mathrm{S}$ and NS is shown in Table 2 ( 0 days, $40 \%$ vs $20 \%$; 1 day, $33 \%$ vs $30 \%$; more than 2 days, $26 \%$ vs $50 \%$ ). More than $70 \%$ of the patients in group $\mathrm{S}$ were administrated rTM within 1 day from the onset of disease causing DIC. Administration of rTM in group $\mathrm{S}$ was significantly earlier from the onset of disease causing DIC $(p=0.030)$. The relationship of time duration between the onset of disease and rTM administration (as $X$ factor) with survival rate (as $Y$ factor) is shown in Figure 2.

\section{Severity of illness and treatment for DIC}

At the start of rTM administration, the APACHEII and SOFA scores were significantly lower in group $\mathrm{S}$ as
Table 1 Patients' background before administration of recombinant thrombomodulin

\begin{tabular}{|c|c|c|c|}
\hline & $\begin{array}{l}\text { Group S } \\
(n=57)\end{array}$ & $\begin{array}{l}\text { Group NS } \\
(n=44)\end{array}$ & $p$ value \\
\hline Age, years, mean $\pm S D$ & $68 \pm 17$ & $75 \pm 11$ & 0.036 \\
\hline Height, $\mathrm{cm}$, mean \pm SD & $157 \pm 8$ & $157 \pm 8$ & 0.71 \\
\hline Weight, kg, mean \pm SD & $49 \pm 10$ & $58 \pm 12$ & $<0.001$ \\
\hline $\mathrm{BMI}, \mathrm{kg} / \mathrm{m}^{2}$, mean $\pm \mathrm{SD}$ & $20 \pm 4$ & $23 \pm 4$ & $<0.001$ \\
\hline Gender, female, $n$ & 27 & 10 & 0.011 \\
\hline Infection-induced DIC, $n$ & 48 & 38 & 0.76 \\
\hline Intra-abdominal, $n$ & 29 & 24 & \\
\hline Lung, $n$ & 9 & 10 & \\
\hline Urinary, $n$ & 3 & 0 & \\
\hline Others, $n$ & 7 & 4 & \\
\hline Non-infection-induced DIC, $n$ & 9 & 6 & 0.34 \\
\hline Obstetric, $n$ & 2 & 0 & \\
\hline Intestinal ischemia, $n$ & 2 & 3 & \\
\hline Others, $n$ & 5 & 3 & \\
\hline Heart disease, $n$ & 12 & 15 & 0.14 \\
\hline Diabetes mellitus, $n$ & 15 & 16 & 0.27 \\
\hline Hypertension, $n$ & 30 & 22 & 0.79 \\
\hline Smoking, $n$ & 19 & 22 & 0.091 \\
\hline
\end{tabular}

$B M I$ body mass index, DIC disseminated intravascular coagulation.

shown in Table $2(26 \pm 6$ vs $32 \pm 6, p<0.001 ; 9.5 \pm 4.2$ vs $13.4 \pm 3.6, p<0.001)$. Although the DIC scores at the start of rTM administration were not significantly different in both groups, the DIC score at the end of rTM administration in group $\mathrm{S}$ was significantly lower than that in group NS. The use of continuous renal replacement therapy (CRRT) was significantly higher in group NS ( $58 \%$ vs $91 \%, p<0.001)$. The rate of mechanical ventilation with intratracheal intubation in group NS was significantly higher than that in group S. The duration of mechanical ventilation with intratracheal intubation was significantly shorter in group S $(11 \pm 17$ vs $23 \pm 38$ days, $p=0.038)$.

\section{Hemorrhagic complications}

Hemorrhagic complications occurred in two patients (2.0\%). Of the two patients, one who received rTM combined with gabexate mesilate for 2 days developed bleeding of the ocular fundus. Another patient with cirrhosis (Child-Pugh classification B) developed a respiratory tract hemorrhage. Multivariate logistic regression analysis of outcomes was performed (Table 3).

\section{Multivariate logistic regression analysis for outcome}

The duration of time between the onset of disease causing DIC and rTM administration, the APACHEII score, the SOFA score, and CRRT use were selected as 
Table 2 Severity of illness and treatment for disseminated intravascular coagulation

\begin{tabular}{llll}
\hline & $\begin{array}{l}\text { Group S } \\
(\boldsymbol{n}=\mathbf{5 7})\end{array}$ & $\begin{array}{l}\text { Group NS } \\
(\boldsymbol{n}=\mathbf{4 4})\end{array}$ & $\boldsymbol{p}$ value \\
\hline rTM treatment duration, days, mean \pm SD & $6.1 \pm 2.9$ & $6.4 \pm 8.4$ & 0.78 \\
Dose of rTM, U/kg/day, mean \pm SD & $345 \pm 108$ & $308 \pm 100$ & 0.083 \\
Duration from onset to rTM, $n(\%)$ & & & 0.030 \\
0 days & $23(40)$ & $9(20)$ & \\
1 day & $19(33)$ & $13(30)$ & \\
2 days & $15(26)$ & $22(50)$ & \\
APACHEll at start of rTM, mean \pm SD & $26 \pm 6$ & $32 \pm 6$ & $<0.001$ \\
SOFA at start of rTM, mean \pm SD & $9.5 \pm 4.2$ & $13.4 \pm 3.6$ & $<0.001$ \\
DIC score at start of rTM, mean \pm SD & $5.2 \pm 1.8$ & $5.6 \pm 1.7$ & 0.20 \\
DIC score at end of rTM, mean \pm SD & $3.0 \pm 2.0$ & $4.9 \pm 1.9$ & $<0.001$ \\
Ventilation with tracheal intubation, $n(\%)$ & $47(82)$ & $43(98)$ & 0.01 \\
Duration of ventilation, days, mean $\pm S D$ & $11 \pm 17$ & $23 \pm 38$ & 0.038 \\
CRRT during rTM therapy, $n$ & 33 & 40 & $<0.001$ \\
Antithrombin-III during rTM therapy, $n$ & 36 & 30 & 0.60 \\
Globulin during rTM therapy, $n$ & 26 & 21 & 0.83 \\
Transfusion during rTM therapy, $n$ & 43 & 37 & 0.29 \\
Enteral nutrition during rTM therapy, $n$ & 34 & 18 & 0.11 \\
\hline
\end{tabular}

rTM recombinant thrombomodulin, $U$ unit, Duration from onset to $r T M$ duration from the onset of disease causing DIC to rTM administration, APACHEIl Acute Physiology and Chronic Health Evaluation II, SOFA Sequential Organ Failure Assessment scores, at start of rTM at the start of rTM administration, at end of rTM at the end of rTM administration, DIC score score of DIC criteria of the Japanese Association for Acute Medicine, CRRT continuous renal replacement therapy.

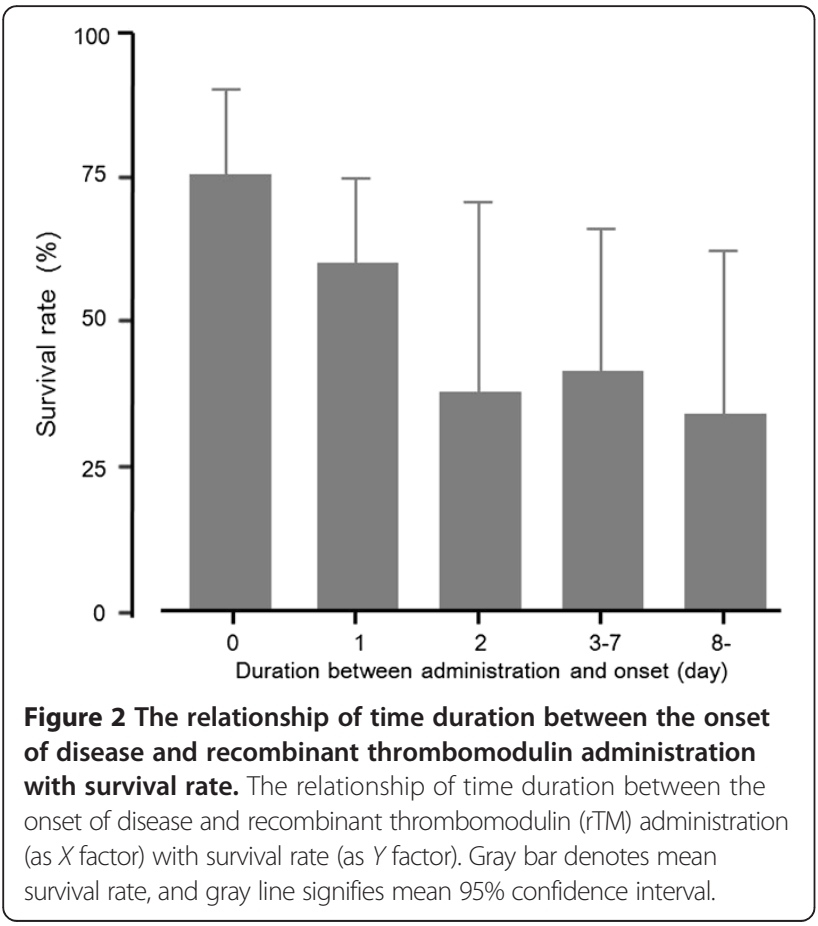

Table 3 Multivariate logistic regression analysis for outcome

\begin{tabular}{lllll}
\hline & Reference & $\begin{array}{l}\text { Adjusted } \\
\text { odds ratio }\end{array}$ & $\begin{array}{l}\text { 95\% confidence } \\
\text { interval }\end{array}$ & $\boldsymbol{p}$ value \\
\hline Gender & Female & 3.39 & $1.19-9.64$ & 0.022 \\
$\begin{array}{l}\text { APACHEIl at } \\
\text { start of rTM }\end{array}$ & & 1.18 & $1.09-1.29$ & $<0.001$ \\
rTM 1 day & 0 days & 1.95 & $0.57-6.62$ & 0.29 \\
rTM 2 days & 0 days & 3.36 & $1.03-10.92$ & 0.044 \\
\hline
\end{tabular}

Hosmer-Lemeshow test (chi-square $=15.13$, degrees of freedom $=8, p=0.057$ ). C-statistics $=0.82$.

APACHEIl Acute Physiology and Chronic Health Evaluation II, rTM recombinant thrombomodulin. rTM $x$ day Duration from the onset of disease to rTM administration was $x$ day, 2 - days more than 2 days.

candidate variables $(p<0.05)$. The SOFA scores and CRRT use were highly correlated with the APACHEII score (Pearson correlation $=0.63$ and 0.43 , respectively). Therefore, the SOFA score and the use of CRRT were excluded from this model. Late administration of rTM (more than 2 days between the onset of disease and rTM administration) was associated with undesirable outcome (odds ratio $=3.36,95 \%$ confidence interval $=1.03-10.92$, $p=0.044)$.

\section{Discussion}

Patients who would benefit from rTM remained unclear. However, the results of this study indicated that the administration of rTM before an increase in the severity of disease causing DIC might be better than that after progression of disease causing DIC if we select rTM for the treatment of DIC. Therefore, we should consider administration of rTM as soon as possible after we diagnose severe diseases with DIC such as sepsis. As clearly shown in this study, the treatment of rTM might not be effective after diseases have progressed and the severity of the patients' conditions, based on the APACHEII and SOFA scores, has increased. Late administration of rTM (more than 2 days from the onset of disease to rTM administration) was associated with a threefold higher risk of undesirable outcomes than early administration. These data suggested that administration of rTM before progression of disease causing DIC might be better than that after progression of disease. The correlation between rTM administration timing and the prognosis of patients with rTM has not been reported. On the other hand, previous reports indicated that APC administration in the advanced phase, for example, in patients with high APACHE II scores (more than 25), was effective, but early administration of APC was not effective [8,9]. We did not compare between these studies about APC and our study because the APACHE II scores in our study were more than 25 . In addition, cases in which early administration of rTM was possible, such as delay of diagnosis of DIC, might exist in our study because of 
a retrospective design. In other words, for example, we could not deny that the diagnosis of DIC might be delayed in general ward because the prothrombin time ratio and the concentration of fibrin/fibrinogen degradation products were not usually measured. In these cases, we might diagnose DIC after ICU admission, although DIC had already occurred before ICU admission. However, we thought that the results of the correlation between rTM administration timing and the prognosis of patients with rTM did not change. Therefore, further randomized clinical trials are required to elucidate whether early administration of rTM is actually effective.

This drug exerts effect of anticoagulation via unique mechanism. The use of rTM promotes protein $C$ activation by thrombin, resulting in the inhibition of thrombin generation, namely, a negative feedback loop [10]. This mechanism might contribute to few hemorrhagic complications. Indeed, a previous study reported that hemorrhagic complications occurred in $8.6 \%$ of patients who received APC [11]. On the other hand, hemorrhagic complications in our study were observed in two patients, but the frequency was as low as $2.0 \%$. One patient who developed bleeding of the ocular fundus improved completely without any medication. Another patient with cirrhosis stopped having a respiratory tract hemorrhage after platelet transfusion because of low platelet count due to DIC and cirrhosis. These patients such as those having serious liver damage and those who use anticoagulation drug might require further attention. Further examination is necessary because this study included only two such patients.

This study has several limitations because of its retrospective design. First, we could not determine the effect of rTM itself because this study did not include a control group in which rTM was not administered, since rTM is the first-line drug for the treatment of DIC in our hospital. At least, the mortality rate in this study was $44 \%$, which is equivalent to or better than those reported in earlier studies [1]. In addition, this study suggested that administration of rTM after progression of disease causing DIC might be less effective. Therefore, the independent effect of rTM compared with other treatments in the early phase of DIC needs to be elucidated in other studies. Second, the therapeutic method was decided by individual physicians. Therefore, the use of CRRT was significantly different. Although many patients in group NS received CRRT, whether death was due to the severity of the underlying disease or whether the results were biased is unclear. In addition, the APACHE II score in group NS was significantly higher than that in group S. However, we performed multivariate logistic regression analysis. At least, we believed that in our study, late administration of rTM tended to be associated with increased mortality. Third, group $\mathrm{S}$ had more number of female patients. Sepsis-related mortality rates are reported to be higher in female patients than in male patients [1]. Although gender was highly associated with the outcomes in our multivariate logistic regression analysis, the late administration of rTM was also a risk factor for mortality. The c-statistics in this model was 0.820 , which suggests that the results of this analysis are reliable. Finally, the age in group NS was higher than that in group S. However, age was included in the components of the APACHEII score. Therefore, age was correlated with the APACHEII score (Pearson correlation $=0.29$ ). In this reason, age was excluded from this model.

\section{Conclusions}

In conclusion, the results of this study suggest that administration of rTM before progression of disease causing DIC might be better for the treatment of DIC than that after progression of disease causing DIC because DIC scores at the start of rTM were not significantly different between groups S and NS. In other words, administration of rTM after progression of disease might be less effective. However, this study was a retrospective study and did not have a control group. Therefore, further randomized clinical trials are required to elucidate whether early administration of rTM is actually effective.

\section{Competing interests}

The authors declare that they have no competing interests.

\section{Authors' contributions}

TY and RN designed this study, collected data, and wrote the manuscript. NK and TI performed the statistical analyses. KY and MY helped design this

study and prepared the manuscript. All authors read and approved the final manuscript.

\section{Author details}

'Department of Anesthesiology and Intensive Care Medicine, Kochi Medical School, Kohasu, Oko-cho, Nankoku City, Kochi 783-8505, Japan. ${ }^{2}$ Department of Advanced Medical Technologies, Kochi Medical School, Kohasu, Oko-cho, Nankoku city, Kochi 783-8505, Japan.

Received: 11 March 2014 Accepted: 11 August 2014

Published: 22 August 2014

\section{References}

1. Singh B, Hanson AC, Alhurani R, Wang S, Herasevich V, Cartin-Ceba R, Kor DJ, Gangat N, Li G: Trends in the incidence and outcomes of disseminated intravascular coagulation in critically ill patients (2004-2010): a populationbased study. CHEST 2013, 143:1235-1242.

2. Saito H, Maruyama I, Shimazaki S, Yamamoto $Y$, Aikawa N, Ohno R, Hirayama A, Matsuda T, Asakura H, Nakashima M, Aoki N: Efficacy and safety of recombinant human soluble thrombomodulin (ART-123) in disseminated intravascular coagulation: results of a phase III, randomized, double-blind clinical trial. J Thromb Haemost 2007, 5:31-41.

3. Vincent JL, Ramesh MK, Ernest D, LaRosa SP, Pachl J, Aikawa N, Hoste E, Levy H, Hirman J, Levi M, Daga M, Kutsogiannis DJ, Crowther M, Bernard GR, Devriendt J, Puigserver JV, Blanzaco DU, Esmon CT, Parrillo JE, Guzzi L, Henderson SJ, Pothirat C, Mehta P, Fareed J, Talwar D, Tsuruta K, Gorelick KJ, Osawa Y, Kaul I: A randomized, double-blind, placebo-controlled, phase $2 b$ study to evaluate the safety and efficacy of recombinant human soluble thrombomodulin, ART-123, in patients with sepsis and suspected disseminated intravascular coagulation. Crit Care Med 2013, 41:2069-2079. 
4. Kato T, Sakai T, Kato M, Hagihara M, Hasegawa T, Matsuura K, Nakagawa T: Recombinant human soluble thrombomodulin administration improves sepsis-induced disseminated intravascular coagulation and mortality: a retrospective cohort study. Thromb J 2013, 11:3.

5. Gando S, Saitoh D, Ogura H, Fujishima S, Mayumi T, Araki T, Ikeda H, Kotani J, Kushimoto S, Miki Y, Shiraishi SI, Suzuki K, Suzuki Y, Takeyama N, Takuma K, Tsuruta R, Yamaguchi Y, Yamashita N, Aikawa N: A multicenter, prospective validation study of the Japanese Association for Acute Medicine disseminated intravascular coagulation scoring system in patients with severe sepsis. Crit Care 2013, 17:R111.

6. Dellinger RP, Levy MM, Rhodes A, Annane D, Gerlach H, Opal SM, Sevransky JE, Sprung CL, Douglas IS, Jaeschke R, Osborn TM, Nunnally ME, Townsend SR, Reinhart K, Kleinpell RM, Angus DC, Deutschman CS, Machado FR, Rubenfeld GD, Webb SA, Beale RJ, Vincent JL, Moreno R: Surviving sepsis campaign: international guidelines for management of severe sepsis and septic shock: 2012. Intensive Care Med 2013, 39:165-228.

7. Dellinger RP, Levy MM, Carlet JM, Bion J, Parker MM, Jaeschke R, Reinhart K, Angus DC, Brun-Buisson C, Beale R, Calandra T, Dhainaut JF, Gerlach H, Harvey M, Marini JJ, Marshall J, Ranieri M, Ramsay G, Sevransky J, Thompson BT, Townsend S, Vender JS, Zimmerman JL, Vincent JL: Surviving sepsis campaign: international guidelines for management of severe sepsis and septic shock: 2008. Intensive Care Med 2008, 34:17-60.

8. Bernard GR, Vincent JL, Laterre PF, LaRosa SP, Dhainaut JF, Lopez-Rodriguez A, Steingrub JS, Garber GE, Helterbrand JD, Ely EW, Fisher CJ Jr: Efficacy and safety of recombinant human activated protein $\mathrm{C}$ for severe sepsis. N Engl J Med 2001, 344:699-709.

9. Abraham E, Laterre PF, Garg R, Levy H, Talwar D, Trzaskoma BL, François B, Guy JS, Brückmann M, Rea-Neto A, Rossaint R, Perrotin D, Sablotzki A, Arkins N, Utterback BG, Macias WL: Drotrecogin alfa (activated) for adults with severe sepsis and a low risk of death. N Engl J Med 2005, 353:1332-1341.

10. Ito T, Maruyama I: Thrombomodulin: protectorate God of the vasculature in thrombosis and inflammation. J Thromb Haemost 2011, 9(Suppl 1):168-173.

11. Ranieri VM, Thompson BT, Barie PS, Dhainaut JF, Douglas IS, Finfer S, Gårdlund B, Marshall JC, Rhodes A, Artigas A, Payen D, Tenhunen J, Al-Khalidi HR, Thompson V, Janes J, Macias WL, Vangerow B, Williams MD: Drotrecogin alfa (activated) in adults with septic shock. N Eng/ J Med 2012, 366:2055-2064.

doi:10.1186/s40560-014-0049-0

Cite this article as: Yatabe et al: Administration of recombinant thrombomodulin before progression of disease causing disseminated intravascular coagulation might be better compared with administration after progression of disease. Journal of Intensive Care 2014 2:49.

\section{Submit your next manuscript to BioMed Central and take full advantage of:}

- Convenient online submission

- Thorough peer review

- No space constraints or color figure charges

- Immediate publication on acceptance

- Inclusion in PubMed, CAS, Scopus and Google Scholar

- Research which is freely available for redistribution 